\title{
Statistical Assessment of Hydraulic Properties of Unsaturated Soils
}

\author{
G.F.N. Gitirana Jr., D.G. Fredlund
}

\begin{abstract}
The availability of statistical values for soil parameters is essential in reliability-based geotechnical design and sensitivity analysis. Unfortunately, there are few statistical studies available about unsaturated soil parameters. The primary objective of this paper is to present a methodology for the statistical assessment of hydraulic properties of unsaturated soil and to present the results of a statistical study carried out using a large database of soil properties. Two fundamental unsaturated soil properties are considered; namely, the soil-water characteristic curve (SWCC) and the hydraulic conductivity function. Appropriate nonlinear functions and fitting parameters with well-defined and unique physical and/or geometrical meanings were adopted. The main contribution of this article is the establishment of central tendency measures, standard deviations, and correlation coefficients for the unsaturated soil parameters, considering soil datasets grouped according to soil texture. It was determined based on the analyses results that the air-entry value, primary SWCC slope, residual SWCC slope, saturated hydraulic conductivity, and hydraulic conductivity function slope could be well described using lognormal probability density functions. Finally, general guidelines are provided regarding the statistical values to be adopted for the unsaturated soil properties studied.
\end{abstract}

Keywords: unsaturated soils, soil-water characteristic curve, hydraulic conductivity, statistics, coefficient of variation, correlation coefficient.

\section{Introduction}

The analysis of unsaturated soil problems can be significantly enhanced and rationalized if the uncertainty associated with the soil properties is addressed through probabilistic analysis. Unfortunately, probabilistic analyses require the knowledge of statistical measures for the input properties involved. The availability of statistical data on unsaturated soil properties benefits a wide range of geotechnical and geoenvironmental problems. Unsaturated/saturated seepage analysis, contaminant transport, and cover/barrier design are some of the major fields that can take advantage of statistical data on unsaturated soil properties. Other areas of application also relevant are those that involve thermal and hydro-mechanical problems.

The main statistical measures required in probabilistic analyses are the central tendency values, standard deviations (or coefficients of variation), and the correlation matrix for the input variables. Typical, representative values for the coefficients of variation and correlation coefficients are often used for the assessment of soil properties in engineering practice. The adoption of a range of typical values is often preferable because it is not feasible to test a large number of soil samples to characterize a particular site (Whitman, 1984; Harr, 1987; Duncan, 2000). Typical central tendency values are also useful but are usually only recommended for preliminary analyses. Numerous studies can be found in the literature suggesting typical coefficients of variation for saturated soil parameters (see references in Table 1). Typical values for correlation coefficients and central tendencies can also be found for saturated soil parameters. Unfortunately, there is limited number of studies presenting statistical assessments for unsaturated soil parameters.

The primary objective of this paper is to present the results of a statistical study carried out using 186 datasets of soil-water characteristic curves and hydraulic conductivity functions. Normality, central tendency measurements, property uncertainty, and correlations coefficients were investigated. The study was directed toward the establishment of guidelines about the typical values expected for different textural groups.

\section{Background}

A review of descriptive statistics applied to geotechnical engineering problems was presented by Ladd (1983). Unbiased estimators can be used for the mean of a random variable, standard deviation, correlation coefficient between two random variables, and autocorrelation coefficient as a function of distance. Most statistical assessment studies found in the geotechnical literature, such as the study by Ladd (1983), deal with the uncertainty of saturated soil parameters. The coefficient of variation, $\mathrm{COV}$, is commonly used as a measure of uncertainty (Harr, 1987). Contrary to the standard deviation, the coefficient of variation can often be assumed to be independent of the magnitude of

Gilson de F. N. Gitirana Jr., PhD., Escola de Engenharia Civil e Ambiental, Universidade Federal de Goias, 74605-220 Goiania, GO, Brazil. e-mail: gilsongitirana@gmail.com.

Delwyn G. Fredlund, PhD., Golder Associates Ltd., 1721 - $8^{\text {th }}$ Street East, Saskatoon, S7H 0T4 SK, Canada. e-mail: del_fredlund@golder.com. Invited Article, no discussion. 
Table 1 - Compilation of coefficients of variation found in the literature for saturated soil parameters.

\begin{tabular}{|c|c|c|}
\hline Property & Coefficient of variation $\mathrm{COV}$ & Source \\
\hline Porosity, $n$ & $10 \%$ & Shultze (1971) \\
\hline Void ratio, $e$ & $10-20 \%$ & Krahn \& Fredlund (1983) \\
\hline Unit weight, $\gamma_{\text {nat }}$ & $3-7 \%$ & Hammitt (1966), Kulhawy (1992), Tan et al. (1993) \\
\hline Friction angle, $\phi '$ & $7-12 \%$ & $\begin{array}{l}\text { Shultze (1971), Lacasse \& Nadim (1997), Duncan } \\
\text { (2000), Phoon \& Kulhawy (1999a) }\end{array}$ \\
\hline Friction angle, $\tan \left(\phi^{\prime}\right)$ & $5-25 \%$ & Lumb (1966), Tan et al. (1993) \\
\hline Cohesion, $c^{\prime}$ & $10-50 \%$ & $\begin{array}{l}\text { Fredlund \& Dahlman (1971), Harr (1987), Kulhawy } \\
\text { (1992), Tan et al. (1993), Lacasse \& Nadim } \\
\text { (1997), Phoon \& Kulhawy (1999a), Duncan (2000) }\end{array}$ \\
\hline Undrained strength, $S_{u}$ & $50-80 \%$ & Krahn \& Fredlund (1983), Phoon \& Kulhawy (1999a) \\
\hline $\begin{array}{l}\text { Saturated water coefficient of } \\
\text { permeability, } k_{\text {sat }}\end{array}$ & $68-90 \%$ & Nielsen et al. (1973), Duncan (2000) \\
\hline $\begin{array}{l}\text { Unsaturated water coefficient of } \\
\text { permeability, } k\end{array}$ & $130-240 \%$ & Nielsen et al. (1973), Benson et al. (1999) \\
\hline Preconsolidation pressure, $\sigma_{p}^{\prime}$ & $10-35 \%$ & $\begin{array}{l}\text { Padilla \& Vanmarcke (1974), Lacasse \& Nadim } \\
\text { (1997), Duncan (2000) }\end{array}$ \\
\hline Compression index, $C_{c}$ & $10-37 \%$ & $\begin{array}{l}\text { Lumb (1966), Padilla \& Vanmarcke (1974), Krahn \& } \\
\text { Fredlund (1983), Kulhawy (1992), Duncan (2000) }\end{array}$ \\
\hline
\end{tabular}

the variable. One shortcoming is that the equation defining COV breaks down when the mean value approaches zero.

Uncertainty of soil parameters can be due to several factors. Whitman (1984) identified four sources of parameter uncertainty; namely, (i) inherent spatial variability; (ii) random testing errors; (iii) statistical error due to a finite number of samples; and (iv) measurement bias. Spatial variability and random testing errors are characterized as scatter in the data. Data scatter averages over large soil volumes and its contribution to parameter uncertainty decreases as the volume of the problem increases. The other two sources of variability are systematic errors that do not average out over the soil volume and have a significant influence on overall uncertainty.

Phoon \& Kulhawy (1999a, 1999b) presented a detailed conceptual description where the sources of soil property uncertainty were divided into inherent variability, measurement variability, and estimation model uncertainty. In addition, an extensive literature review was conducted to collect information required to determine typical inherent soil variability, scales of spatial fluctuation, measurement error variability, and transformation uncertainty. The authors observed that the COV of inherent variability for sand is higher than that for clays. Phoon \& Kulhawy (1999a) also observed that index parameters present lower values of $\mathrm{COV}$ when compared to the COV of shear strength parameters and soil modulus. Unsaturated soil properties were not addressed by their study.

Dai \& Wang (1992) and Duncan (2000) indicate that the three-sigma rule provides a useful approximation for the coefficients of variation of geotechnical properties.
Since $99.73 \%$ of all values of a normally distributed parameter fall within three standard deviations of the mean value, the following equation can be used to estimate the coefficient of variation of a parameter:

$$
\operatorname{COV}[x]=\frac{1}{\mathrm{E}[x]} \frac{\mathrm{HCV}-\mathrm{LCV}}{6}
$$

where $\mathrm{E}[x]$ is the mean value of the parameter $x, \mathrm{HCV}$ is the highest conceivable value, and LCV is the lowest conceivable value of the parameter $x$.

There is a tendency to estimate ranges of conceivable values that are smaller than the real ranges. Duncan (2000) observed that with practice and experience the subjective estimation exercise becomes more accurate. It was also suggested that "an effort should be made to make the range of conceivable values as wide as seemingly possible or even wider, to overcome the natural tendency to make the range too small."

The three-sigma rule was conceived as a substitute to the application of conventional descriptive statistics on measured soil parameters. Conventional descriptive statistics are rarely used in geotechnical engineering practice because the number of samples and tests required to obtain values of statistical significance is prohibitive for most projects. The cost of the tests and the time available are simply too great. Other alternative often adopted is the use of published values of typical coefficients of variation obtained from past studies.

Table 1 presents a compilation of some values of coefficient of variation from published data. The ranges presented envelop values provided from several sources. The 
information available in the literature enables the application of reliability-based design into geotechnical practice. It is interesting to note that cohesion, undrained strength and permeability present considerably higher COVs. The COV of porosity and void ratio found in the literature are of particular interest to the present study, since the range of published values can be compared with the value presented herein.

Unsaturated soil properties are generally defined as nonlinear functions of the stress state variables. The nonlinear characteristics of such soil properties require a somewhat more elaborate procedure for statistical assessment than that adopted for saturated soil properties. Confidence bands are often used in the statistical characterization of functions (Bates \& Watts, 1988). This was the approach used in the statistical characterization of the SWCC by Mishra et al. (1989) and Zapata et al. (2000). Both authors were able to establish typical ranges of variability expected for SWCCs. Unfortunately, such an approach is not convenient for reliability analysis. Reliability analyses can be more easily undertaken if property variability is characterized in terms of the variability of a finite and relatively small number of curve parameters. A small number of authors, such as Meyer et al. (1997), Rawls et al. (1998), Faulkner et al. (2003) and Phoon et al. (2010), have presented statistical and probabilistic studies regarding some of the hydraulic properties of unsaturated soils. Unfortunately, these studies are based on specific fitting functions whose parameters have little or no physical meaning and are not independently related to individual shape features of the unsaturated soil property functions.

\section{Methodology for the Statistical Assessment of Unsaturated Soil Properties}

The statistical assessment of unsaturated soil properties requires the establishment of an appropriate methodology regarding the selection of data and analysis procedure. This section presents the criteria established for data selection and data grouping, the fitting equation that have been used in this study, and the fitting procedure adopted.

\subsection{Soil properties studied and criteria for selection of data records}

The properties studied in this paper are for the soilwater characteristic curve, SWCC, and the hydraulic conductivity function. Data records were sampled from a soils database (SoilVision Systems, 2005). Only drying curves were used in the present study, as those are the most commonly measured and found in the literature.

Other unsaturated soil properties such as the vapor conductivity, thermal properties, and shear strength were not analyzed in this paper due to the limited availability of data at the present time. However, these unsaturated soil properties can be visualized as variables dependent on the soil-water characteristic curve. There are numerous predic- tive models available based on the SWCC. Consequently, the statistical study presented herein for the SWCC becomes useful for the assessment of other unsaturated soil properties. A complete statistical assessment of all unsaturated soil properties would also require studies on the uncertainties associated with the predictive models.

The term hydraulic conductivity function is used herein to denote the relationship between the hydraulic conductivity and soil suction. The hydraulic conductivity function can also be treated as a property dependent on the SWCC. Huang et al. (1998) presents a review of several hydraulic conductivity prediction methods. However, the relatively large amount of directly measured hydraulic conductivity data available provided an opportunity for the independent analysis presented in this study.

A total of 186 soil records were sampled from the SoilVision database. The number of sampled records was limited by the number of available "complete" soil records. To be considered "complete", a soil record was required to have a grain-size distribution, the soil porosity, $n$, the drying soil-water characteristic curve, the saturated hydraulic conductivity, and the hydraulic conductivity function. The porosity data provided an indication of total water storage. The grain-size distribution was required for the classification of each soil sample and grouping the soil data with respect to texture.

\subsection{Fitting equations and corresponding soil parame- ters}

The soil-water characteristic curve and the hydraulic conductivity function can be described using various equations (Fredlund and Xing 1994) whose soil parameters can be treated as best-fit parameters obtained using a nonlinear fitting algorithm. Unfortunately, unsaturated soil property functions have often been defined using functions whose fitting-parameters have limited physical significance and are somewhat interrelated. For instance, for most SWCC equations it is possible to obtain similar fitting with completely different sets of parameters (Gitirana Jr. \& Fredlund, 2004). In other words, the set of best-fit parameters do not appear to be unique. Consequently, it becomes difficult to perform a meaningful statistical analysis on such parameters. In order to overcome these difficulties, it is suggested herein that it is better to use soil property functions defined by mathematically independent and preferably meaningful soil parameters.

\subsubsection{Soil-water characteristic curve equation}

The soil-water characteristic curve datasets were fitted using the unimodal equations proposed by Gitirana Jr. \& Fredlund (2004). Two equations were used herein; namely, the unimodal equation with two bending points and the unimodal equation with one bending point. The unimodal equation with two bending points can be written as follows: 
$S=\frac{S_{1}-S_{2}}{1+\left(\frac{\psi}{\sqrt{\psi_{b} \psi_{\text {res }}}}\right)^{d}}+S_{2}$

$S_{i}=\frac{\tan \theta_{i}\left(1+r_{i}^{2}\right) \ln \left(\frac{\psi}{\psi_{i}^{a}}\right)}{1+r_{i}^{2} \tan ^{2} \theta_{i}}+(-1)^{i} \cdot \frac{1+\tan ^{2} \theta_{i}}{1-r_{i}^{2} \tan ^{2} \theta_{i}}$.

$\sqrt{r_{i}^{2} \ln ^{2}\left(\frac{\psi}{\psi_{i}^{a}}\right)+\frac{a^{2}\left(1-r_{i}^{2} \tan ^{2} \theta_{i}\right)}{1+\tan ^{2} \theta_{i}}}+S_{i}^{a}$

where $i=1,2 ; \theta_{i}=-\left(\lambda_{i-1}+\lambda_{i}\right) / 2 ; r_{i}=\tan \left(\left(\lambda_{i-1}-\lambda_{i}\right) / 2\right) ; \lambda_{0}=0$; $\lambda_{i}=\arctan \left[\left(S_{i}^{a}-S_{i+1}^{a}\right) /\left(\ln \left(\psi^{a}{ }_{i+1} / \psi^{a}\right)\right)\right] ; S_{1}^{a}=1 ; S_{2}^{a}=S_{r e s}$; $S_{3}{ }^{a}=0 ; \psi_{1}{ }^{a}=\psi_{b} ; \psi_{2}{ }^{a}=\psi_{\text {res }} ; \psi_{3}{ }^{a}=10^{6} ; d=2 \exp \left(1 / \ln \left(\psi_{\text {res }} / \psi_{b}\right)\right)$; $\psi=$ soil suction; and $a$ is a parameter controlling the curve sharpness at the two bending points.

The unimodal equation with one bending point can be obtained directly from Eq. 3, making $S=S_{1}, \theta_{1}=-\lambda / 2$, $r_{1}=\tan (\lambda / 2)$, and $\lambda=\arctan \left[1 /\left(\ln \left(10^{6} / \psi_{b}\right)\right)\right]$.

According to Eq. 2, a SWCC with two bending points can be defined using four parameters; namely, $\psi_{b}=$ airentry value; $\psi_{\text {res }}=$ residual suction; $S_{\text {res }}=$ residual degree of saturation; and the sharpness parameter, $a$. These four parameters correspond to the number of shape features of a typical SWCC (see Fig. 1). Figure 1 also shows that two shape features define a SWCC with one bending point; namely, $\psi_{b}$ and $a$. Each one of these soil parameters have a physical meaning (Gitirana Jr. \& Fredlund, 2004).

Other SWCC parameters are defined in Fig. 1; namely, $\lambda_{d}$, the primary drainage slope; and $\lambda_{\text {res }}$, the residual drainage slope. The primary and residual drainage slopes can be calculated as follows:

$$
\lambda_{d}=\frac{1-S_{\text {res }}}{\log _{10}\left(\frac{\psi_{\text {res }}}{\psi_{b}}\right)}
$$

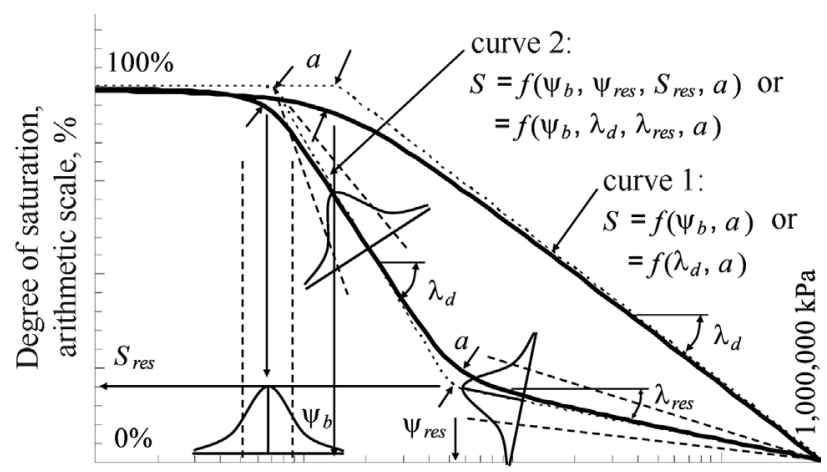

Soil suction, log scale, $\mathrm{kPa}$

Figure 1 - Idealization of a unimodal soil-water characteristic curve with one and two bending points.

$$
\lambda_{\text {res }}=\frac{S_{r e s}}{\log _{10}\left(\frac{1,000,000}{\psi_{\text {res }}}\right)}
$$

The primary drainage slope, $\lambda_{d}$, is influenced by the distribution of the pore-sizes. Uniform pore-size distributions result in steeper primary drainage slopes.

Four parameters should be used to describe the SWCC because the curve has four distinct shape features. The use of a number of parameters lower than four would impose restrictions to the SWCC shape. The set of parameters $\psi_{b}, \lambda_{d}, \lambda_{\text {res }}$, and $a$ was deemed to be appropriate for this study. For instance, difficulties in probabilistic analyses would arise for estimate points (or random realizations) of $\psi_{b}$ greater than $\psi_{\text {res }}$, a combination of parameters that is physically inadmissible. The use of constraints to prevent $\psi_{b}>\psi_{\text {res }}$ is mathematically cumbersome and, as a result, $\psi_{\text {res }}$ and $S_{r e s}$ were replaced by $\lambda_{d}$ and $\lambda_{\text {res }}$.

Most sampled SWCC datasets show curves with two bending points (e.g., curve 2 in Fig. 1). However, most clay soils have SWCCs with only one bending point and do not present a distinguishable residual point (e.g., curve 1 in Fig. 1). As a result, all clay datasets were fitted using the unimodal equation with one bending point, while other soil types where fitted using an equation with two-bending points.

Gitirana Jr. \& Fredlund (2004) show that the parameter $a$ slightly improves the fitting capabilities of the equation. However, the physical meaning of $a$ is not as clear and as significant as the physical meaning of the other three SWCC parameters. Therefore, fixed values were adopted for $a$, based on the observation that a good fit could be obtained for the absolute majority of data when using the chosen values. A value of $a$ equals to 0.075 was selected for all Sands, 0.050 was selected for Loams, and 0.025 was selected for Clays.

\subsubsection{Hydraulic conductivity function}

The hydraulic conductivity function datasets were fitted using a bi-linear function on a $\log v s$. log plot (see Fig. 2). The bi-linear shape was found to fit reasonably well most experimental curves. The first portion of the curve is defined using a constant value equal to the saturated hydraulic conductivity, $k_{\text {sat }}$. The value of $k_{\text {sat }}$ was not treated as a fitting parameter but as an independently measured value. The second portion of the curve was assumed to be defined by a constant slope, $\eta$. The following bi-linear equation was used (Brooks \& Corey, 1964):

$$
\begin{array}{ll}
k=k_{s a t} & \text { for } \psi \leq \psi_{b k} \\
k=k_{s a t}\left[\frac{\psi_{b k}}{\psi}\right]^{n} & \text { for } \psi>\psi_{b k}
\end{array}
$$




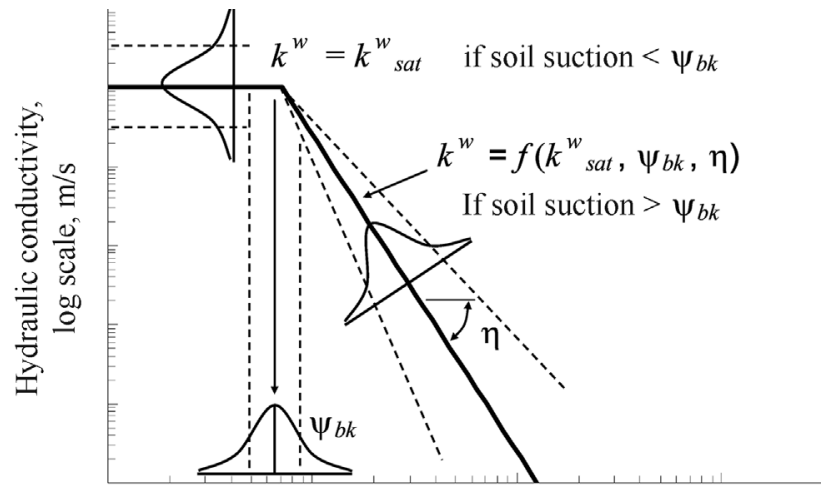

Soil suction, $\log$ scale, $\mathrm{kPa}$

Figure 2 - Idealization of a hydraulic conductivity function.

where $k=$ hydraulic conductivity; $k_{\text {sat }}=$ saturated hydraulic conductivity; $\psi_{b k}=$ break point of the hydraulic conductivity function; $\eta=$ slope of the hydraulic conductivity function.

In theory, the break point, $\psi_{b k}$, corresponds to the air-entry value, $\psi_{b}$. However, it was found that the air-entry value obtained from the SWCC fitting does not always match the break point observed in the hydraulic conductivity function. The use of $\psi_{b k}$ equal to $\psi_{b}$ would compromise the fitting capability of Eq. 6 . As a result, the fitting of the hydraulic conductivity function was made independently of the soil-water characteristic curve fit (i.e., the air-entry value from the SWCC was not used for the hydraulic conductivity function).

\subsection{Fitting procedure and statistical representation of unsaturated soil property functions}

The following soil parameters were statistically assessed, in order to completely define the SWCC and hydraulic conductivity function: $\psi_{b}, \lambda_{d}, \lambda_{r e s}, k_{s a t}, \psi_{b k}$, and $\eta$. The data records sampled from the SoilVision database were first imported into a spreadsheet. The fitting of the SWCCs and hydraulic conductivity functions was performed by minimizing the sum of the squared residuals between the experimental data and the fitting curve. The nonlinear minimization solver available in MS Excel $^{\oplus}$ was utilized. The nonlinear fitting application appeared to perform well provided that the initial guess was sufficiently close to the final best-fit parameter. Other minimization techniques are available and some of these have been described by Fredlund \& Xing (1994).

Figures 1 and 2 illustrate the manner in which the soil-water characteristic curve and the hydraulic conductivity function can be statistically described based on the statistical characterization of the soil parameters $\psi_{b}, \lambda_{d}, \lambda_{\text {res }}$, $k_{s a t}, \psi_{b k}$, and $\eta$. Each soil parameter was considered as a random variable with a frequency distribution characterized based on statistical descriptive measures, as traditionally done for other soil properties.

\subsection{Soil grouping based on the USDA textural classifi- cation system}

The 186 soil records sampled from the SoilVision database are diverse soils with distinct characteristics. Ideally, the statistical assessment of individual "soil groups" is preferable (Fredlund \& Dahlman, 1971) even though the definition of the term "soil group" is not totally precise. To address that concern, the sampled records were grouped according to their textural characteristics. The separation of soil types is an attempt to group soils with similar engineering behavior, even though soil behavior depends on many other characteristics.

Two of the commonly used soil classification systems are the USDA system (Soil Survey Staff, 1975) and the Unified Soil Classification System, USCS, (ASTM, 1993). The USCS system is generally preferred in geotechnical engineering. However, the number of "complete" records in the SoilVision database where Atterberg limits are presented is small. As a result, the USDA system has been adopted herein.

Figure 3 presents the textural diagram used in the USDA soil classification system (Soil Survey Staff, 1975) along with the textural characteristics of the data records sampled. The percentages of sand, silt and clay plotted in Fig. 3 were defined using the following particle size, $x$, intervals: Clay: $x<0.002 \mathrm{~mm}$; Silt: $0.002 \leq x<0.05 \mathrm{~mm}$; Sand: $0.05 \leq x<2 \mathrm{~mm}$; and Coarse material: $2 \leq x<300 \mathrm{~mm}$.

Three main groups are identified in Fig. 3; namely, sands $(S a)$, loams $(L)$, and clays $(C)$. The silt and silty fractions $(\mathrm{Si})$ are placed within the loam fraction. The number of sampled records pertaining to each soil group is 62, making a total of 186 sampled records. Each of the three main soil groups is subdivided into a number of subgroups ( $\mathrm{Sa}$,

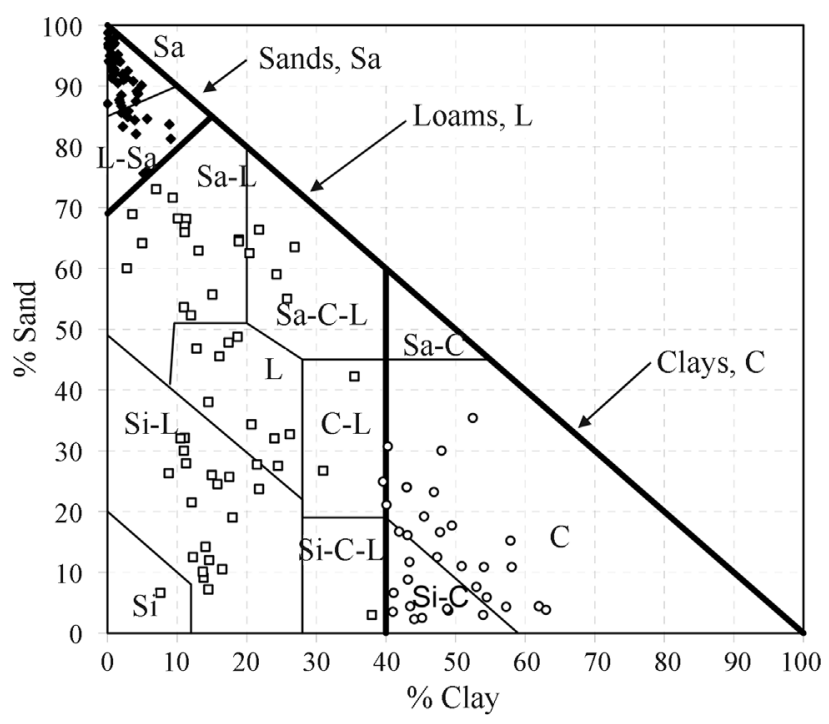

Figure 3 - Sampled soil records classified according to the USDA classification system. 
$L-S a, S a-L, S a-C-L, L, S i-L, S i, C-L, S i-C-L, S a-C, S i-C$, and $C$ ).

\section{Results and Discussion of Normality Tests}

Normality tests were performed on the soil parameters and on the natural logarithm of most soil parameters in order to determine whether normal or lognormal density functions reasonably represent each unsaturated soil parameter. Normality tests were performed with the aid of Minitab 13 (Minitab Inc., 2000). Minitab has three hypothesis tests available for testing normality; namely, Anderson-Darling test; Ryan-Joiner test; and Kolmogorov-Smirnov test. D'Augostino \& Stevens (1986) present detailed descriptions and comparisons of these tests for normality. The Anderson-Darling test has relatively superior power for detecting non-normality and was selected. The null hypothesis for the Anderson-Darling test is " $\mathrm{HO}$ : data follow a normal distribution". The results of the normality tests are presented in terms of $p$-values. $P$-values represent the probability of making a type 1 error, which is "rejecting the null hypothesis when it is true." A cut-off value often used was $5 \%$, which means "reject the null hypothesis when the $p$-value is less than 5\%" (D'Augostino and Stevens 1986).

Sampled records were grouped according to the USDA classification system, as presented in Fig. 3. For the normality tests the analyses were carried out following three distinct procedures: a) considering all the sampled records as one single group; b) assembling the data using the three main groups of soils (i.e., Sa, $L$, and $C$ ); and c) assembling the data using the smaller soils subgroups indicated in Fig. 3. The soil subgroups $S i, C-L, S i-C-L$, and $S a-C$ could not be analyzed because of the relatively small number of sample records in those subgroups.

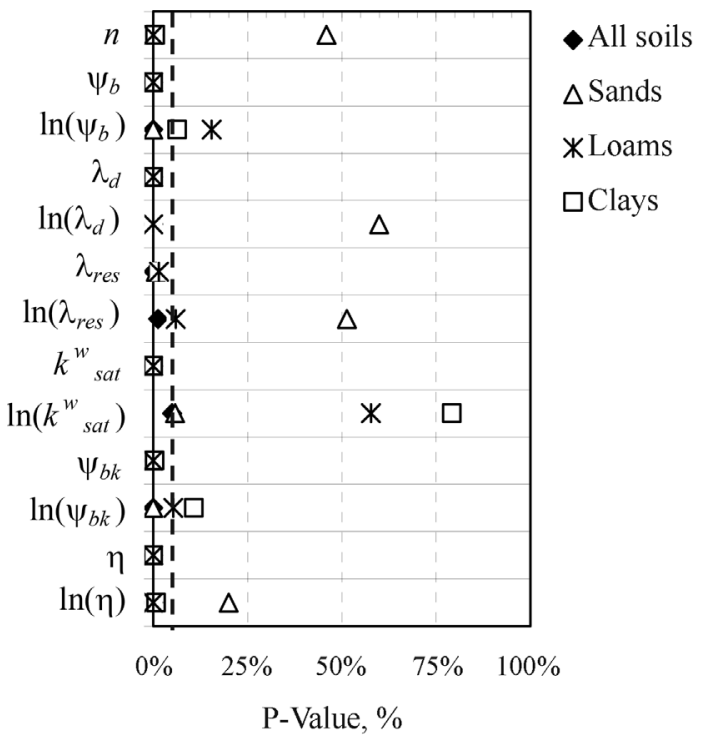

(a)
Figure 4 present the results of the normality tests in terms of $p$-values. Dashed lines indicate the threshold of $5 \%$, below which normality is unlikely. Figure 4 shows that most parameters and soil groups deviate to some extent from a normal distribution. This is particularly true for $\psi_{b}$, $\lambda_{d}, \lambda_{r e s}, k_{s a t}, \psi_{b l}$, and $\eta$. When the logarithm of $\psi_{b}, \lambda_{d}, \lambda_{r e s}, k_{s a t}$, $\psi_{b k}$, and $\eta$ were tested the parameters were closer to being normally distributed (i.e., larger $p$-values). Based on the results presented in Fig. 4, it was concluded that the parameters $\psi_{b}, \lambda_{d}, \lambda_{r e s}, k_{s a t}, \psi_{b k}$, and $\eta$ can be considered log normally distributed while $n$ is reasonably described using a normal distribution.

The effect to the normality tests of grouping soil data into textural classes can be clearly observed in Fig. 4. None of the parameters were found to be normally or log normally distributed when all sampled records were analyzed as a single soil. The more detailed soil textural classification (Fig. 4b) appears to produce parameter distributions that are better described by normal and lognormal distributions.

\section{Results and Discussion of Descriptive Statistics Analysis}

Tables 2 and 3 present descriptive statistical parameters obtained for the three main soil groups; namely, sands $(S a)$, loams $(L)$, and clays $(C)$. The minimum and maximum values are presented along with measures of central tendency and the standard deviation. Three measures of central tendency were calculated; namely, the median, the mean, and the global best-fit parameters. The global best-fit parameters were obtained by assembling in the same plot all the datasets pertaining to a given soil group.

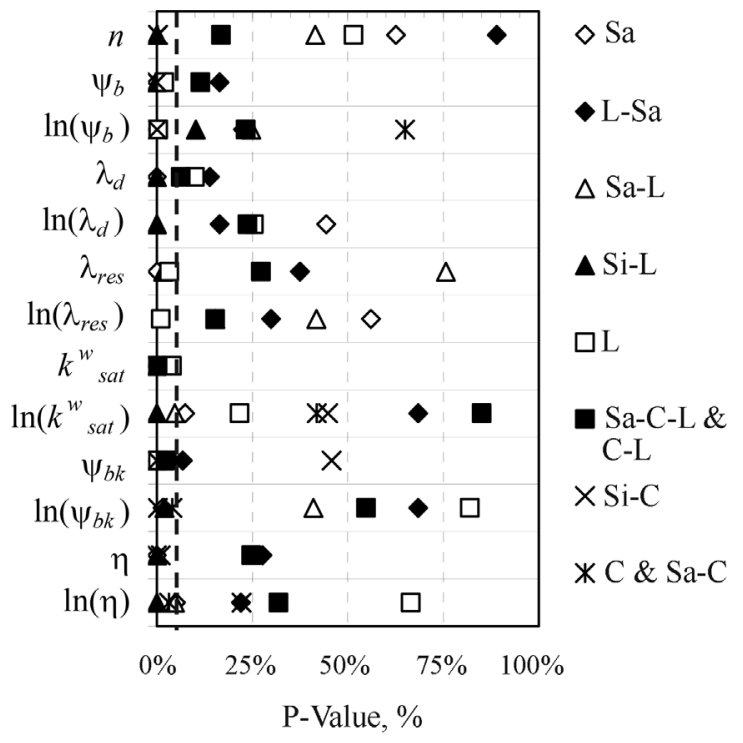

(b)

Figure 4 - Normality tests: $p$-values for all soil parameters considering (a) the three main soil groups and (b) all soil subgroups. 
Table 4 presents a summary of the coefficients of variation, COV, obtained from the statistical analyses. Two main measures are usually considered in the quantification of uncertainty; namely, the standard deviation,
$\mathrm{SD}$, and the coefficient of variation. The standard deviation of a random variable is strongly influenced by the mean values and depends on the units of the variable. The coefficient of variation tends to offer a means of normal-

Table 2 - Descriptive statistics for unsaturated soils properties ( $a=0.075$ for sands, 0.050 for loams, and 0.025 for clays).

\begin{tabular}{llccccccc}
\hline Group & Measure & $n$ & $\psi_{b}(\mathrm{kPa})$ & $\lambda_{d}$ & $\lambda_{\text {res }}$ & $k_{\text {sat }}(\mathrm{m} / \mathrm{s})$ & $\psi_{b k}(\mathrm{kPa})$ & $\eta$ \\
\hline Sands & Min & 0.297 & 0.183 & 0.405 & 0.019 & $3.8 \times 110^{-7}$ & 0.100 & 1.288 \\
& Max & 0.570 & 12.00 & 4.228 & 0.126 & $3.50 \times 10^{-4}$ & 7.239 & 10.500 \\
& Median & 0.409 & 2.438 & 1.178 & 0.044 & $1.82 \times 10^{-5}$ & 1.585 & 3.484 \\
& Mean & 0.410 & 2.937 & 1.446 & 0.047 & $3.88 \times 10^{-5}$ & 1.874 & 4.037 \\
& Global best-fit & - & 1.64 & 0.844 & 0.049 & $7.06 \times 10^{-6}$ & 1.550 & 3.107 \\
& Std. Dev. & 0.055 & 2.050 & 0.880 & 0.021 & $6.34 \times 10^{-5}$ & 1.582 & 2.141 \\
Loams & Min & 0.378 & 0.054 & 0.177 & 0.038 & $3.49 \times 10^{-8}$ & 0.040 & 1.027 \\
& Max & 0.715 & 40.000 & 2.471 & 0.144 & $1.33 \times 10^{-4}$ & 10.000 & 7.657 \\
& Median & 0.471 & 2.697 & 0.371 & 0.087 & $3.23 \times 10^{-6}$ & 1.000 & 2.057 \\
& Mean & 0.501 & 4.398 & 0.633 & 0.090 & $1.42 \times 10^{-5}$ & 2.032 & 2.792 \\
& Global best-fit & - & 1.351 & 0.334 & 0.103 & $3.14 \times 10^{-6}$ & 0.830 & 1.954 \\
& Std. Dev. & 0.085 & 6.190 & 0.571 & 0.025 & $2.50 \times 10^{-5}$ & 2.261 & 1.624 \\
& Min & 0.351 & 0.500 & - & - & $5.42 \times 10^{-10}$ & 0.030 & 1.094 \\
& Max & 0.790 & 4932.4 & - & - & $5.88 \times 10^{-6}$ & 6.000 & 4.933 \\
& Median & 0.544 & 2.11 & - & - & $1.17 \times 10^{-7}$ & 2.078 & 2.000 \\
& Mean & 0.534 & 91.4 & - & - & $5.51 \times 10^{-7}$ & 2.363 & 2.095 \\
& Global best-fit & - & 2.505 & - & - & $1.39 \times 10^{-6}$ & 0.179 & 1.571 \\
& Std. Dev. & 0.100 & 626.1 & - & - & $1.16 \times 10^{-6}$ & 1.614 & 0.791 \\
\hline
\end{tabular}

Table 3 - Descriptive statistics for the natural logarithm of unsaturated soil properties ( $a=0.075$ for sands, 0.050 for loams, and 0.025 for clays).

\begin{tabular}{|c|c|c|c|c|c|c|c|}
\hline Group & Measure & $\ln \left(\psi_{b}\right) \ln (\mathrm{kPa})$ & $\ln \left(\lambda_{d}\right)$ & $\ln \left(\lambda_{r e s}\right)$ & $\ln \left(k_{\text {sat }}\right) \ln (\mathrm{m} / \mathrm{s})$ & $\ln \left(\psi_{b k}\right) \ln (\mathrm{kPa})$ & $\ln (\eta)$ \\
\hline \multirow[t]{5}{*}{ Sands } & Min & -1.701 & -0.904 & -3.968 & -14.78 & -2.303 & 0.253 \\
\hline & Max & 2.485 & 1.442 & -2.068 & -7.96 & 1.979 & 2.351 \\
\hline & Median & 0.891 & 0.163 & -3.119 & -10.91 & 0.461 & 1.248 \\
\hline & Mean & 0.856 & 0.198 & -3.141 & -11.34 & 0.119 & 1.268 \\
\hline & Std. Dev. & 0.733 & 0.592 & 0.430 & 1.736 & 1.180 & 0.506 \\
\hline \multirow[t]{5}{*}{ Loams } & Min & -2.914 & -1.734 & -3.270 & -17.17 & -3.219 & 0.027 \\
\hline & Max & 3.689 & 0.905 & -1.940 & -8.92 & 2.303 & 2.036 \\
\hline & Median & 0.992 & -0.991 & -2.446 & -12.64 & 0.000 & 0.721 \\
\hline & Mean & 0.927 & -0.737 & -2.445 & -12.58 & -0.047 & 0.895 \\
\hline & Std. Dev. & 1.090 & 0.689 & 0.291 & 1.870 & 1.391 & 0.492 \\
\hline \multirow[t]{5}{*}{ Clays } & Min & -1.049 & - & - & -21.34 & -3.507 & 0.089 \\
\hline & Max & 8.504 & - & - & -12.04 & 1.792 & 1.596 \\
\hline & Median & 0.743 & - & - & -15.96 & 0.731 & 0.693 \\
\hline & Mean & 0.999 & - & - & -16.03 & 0.527 & 0.682 \\
\hline & Std. Dev. & 2.064 & - & - & 2.053 & 0.992 & 0.331 \\
\hline
\end{tabular}


Table 4 - Coefficients of variation for unsaturated soil properties.

\begin{tabular}{|c|c|c|c|c|c|c|c|c|c|}
\hline Group & Sub-group & Records & $n$ & $\ln \left(\psi_{b}\right)$ & $\ln \left(\lambda_{d}\right)$ & $\ln \left(\lambda_{r e s}\right)$ & $\ln \left(k_{s a t}\right)$ & $\ln \left(\psi_{b k}\right)$ & $\ln (\eta)$ \\
\hline All & - & 186 & 20.2 & 151.6 & 294.4 & 18.1 & 20.6 & 608.8 & 53.7 \\
\hline \multirow[t]{3}{*}{ Sands } & All & 62 & 13.5 & 85.6 & 299.3 & 13.7 & 15.3 & 988.7 & 39.9 \\
\hline & $S a$ & 53 & 12.7 & 92.1 & 279.9 & 13.9 & 15.4 & 5439.9 & 43.0 \\
\hline & $L-S a$ & 9 & 13.7 & 53.2 & 655.6 & 8.5 & 15.3 & 111.3 & 14.4 \\
\hline \multirow[t]{5}{*}{ Loams } & All & 62 & 17.1 & 117.6 & 93.5 & 11.9 & 14.9 & 2962.5 & 55.0 \\
\hline & $S a-L$ & 15 & 11.3 & 105.5 & 74.5 & 10.2 & 13.6 & 539.3 & 60.3 \\
\hline & $S i-L$ & 27 & 13.5 & 74.3 & 133.2 & 11.4 & 15.7 & 365.4 & 57.7 \\
\hline & $L$ & 12 & 18.0 & 684.0 & 49.6 & 8.9 & 13.5 & 177.2 & 33.3 \\
\hline & $S a-C-L \& C-L$ & 8 & 16.3 & 149.2 & 101.0 & 12.2 & 14.3 & 937.3 & 55.3 \\
\hline \multirow[t]{3}{*}{ Clays } & All & 62 & 18.7 & 206.6 & - & - & 12.8 & 188.2 & 48.6 \\
\hline & $S i-C$ & 22 & 26.3 & 125.5 & - & - & 10.4 & 76.5 & 52.2 \\
\hline & $S a-C \& C$ & 40 & 13.4 & 295.2 & - & - & 13.3 & 369.2 & 44.7 \\
\hline
\end{tabular}

izing the standard variation with respect to the mean value. The coefficient of variation is unitless and has been traditionally used for characterizing geotechnical parameter uncertainty.

It was shown in the previous section that the parameters $\psi_{b}, \lambda_{d}, \lambda_{\text {res }}, k_{s a t}, \psi_{b k}$, and $\eta$ can be better analyzed in terms of natural logarithm. Therefore, values of COV are presented for the natural logarithms of all soil parameters, with exception of porosity, which was not considered log normally distributed. The coefficients of variations for $n$, $\ln \left(\psi_{b}\right), \ln \left(\lambda_{d}\right), \ln \left(\lambda_{\text {res }}\right), \ln \left(k_{\text {sat }}\right), \ln \left(\psi_{b k}\right)$, and $\ln (\eta)$ are presented for each USDA group. Some neighboring groups with a reduced number of records where joined, as indicated. The data summarized in Tables 2-4 will be discussed in the following sections.

\subsection{Porosity}

The mean value of porosity, $n$, is 0.410 for sands, 0.501 for loams, and 0.534 for clays. The median values obtained do not differ considerably from the mean. Both the mean and median values appear to provide a reasonable measure of the central tendency for porosity. The minimum, maximum, median, and mean porosities increase for finer-grained soils, as expected.

The standard deviations and coefficients of variation increase for finer-grained soils. The coefficients of variation of porosity were $13.5 \%$ for sands, $17.1 \%$ for loams, and $18.7 \%$ for clays. The values previously reported in the literature show COVs for porosity varying from $10 \%$ to $20 \%$. The results obtained herein suggest that the variability of the soil records studied may be slightly higher than that of soil records obtained from a single location or soil formation.

Figure 5 presents a plot of mean values of porosity $v s$. the computed coefficients of variation. Each data point corresponds to a distinct soil group gathered from the sampled

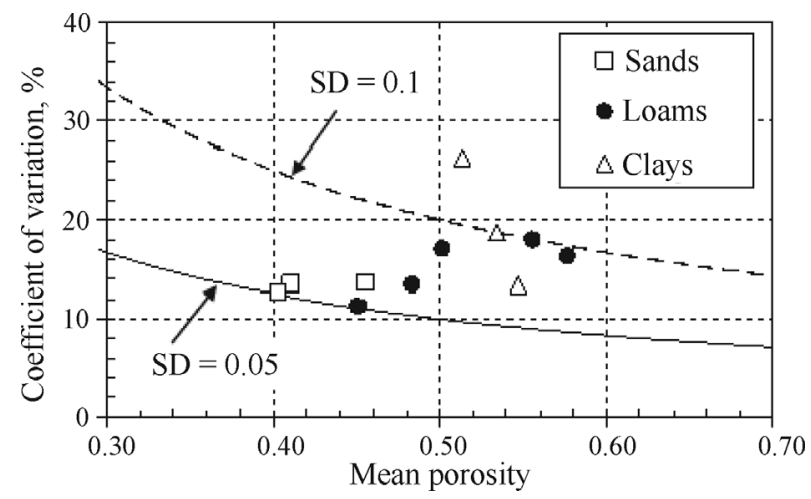

Figure 5 - Mean vs. the coefficient of variation of the soil porosity, $n$.

soil records. The two lines surrounding the data points correspond to constant values of standard deviation, as indicated. One outlier was ignored. The data points plotted in Fig. 5 indicate that the COV for porosity show little variation with the mean value, as is often assumed. Although some of the results presented for porosity may appear obvious, the availability of statistical data in the literature allows comparisons that serve as verifications of the validity of the results obtained.

\subsection{Air-entry value}

The mean air-entry value was $2.9 \mathrm{kPa}$ for sands, 4.4 $\mathrm{kPa}$ for loams, and $91.4 \mathrm{kPa}$ for clays. The median values of $\psi_{b}$ are considerably lower than the mean values, indicating positive skewness in the frequency distribution. However, the mean and median values of $\ln \left(\psi_{b}\right)$ are in reasonable agreement. This observation supports previous observations indicating the log normality of $\psi_{b}$.

The global best-fit values of $\psi_{b}$ appear to be in poor agreement with the mean values of $\psi_{b}$ and in better agree- 
ment with the median values of $\psi_{b}$. The best-fit air-entry value is also in better agreement with the exponential of the mean values of $\ln \left(\psi_{b}\right)$. In other words, the mean values of $\ln \left(\psi_{b}\right)$ appear to be the best measurement of central tendency associated with $\psi_{b}$. The data for the air-entry value obtained from the hydraulic conductivity function lead to the same findings

The maximum and mean air-entry values increased for finer grained soils, as expected. The minimum and median values do not appear to show the same increasing trend. It appears that there are some factors other than the relationship between pore-size distribution and texture that influence the air-entry value. Soil structure, for instance, would appear to have a particularly important effect in the air-entry value of clay soils. Therefore, the values of $\psi_{b}$ of clay soils can vary over a relatively large range and not always be higher than those of sand and loam soils.

Figure 6 presents a comparison of $\psi_{b k}$ and $\psi_{b}$. In theory, the values of $\psi_{b k}$ should be similar to the values of $\psi_{b}$. This tendency is in part confirmed by Fig. 6, with numerous data points near the 1:1 line. However, dispersion is observed and the values of $\psi_{b k}$ tend to be lower than the values of $\psi_{b}$. This trend may be expected for soils that undergo substantial volume changes. Volume changes may cause a decrease in the hydraulic conductivity (Huang et al., 1998). Consequently, a false break point in the hydraulic conductivity function may appear at a value of soil suction slightly below the value of $\psi_{b}$ obtained from the SWCC.

The coefficients of variation obtained for the natural logarithm of the air entry values obtained from the SWCC, $\ln \left(\psi_{b}\right)$, were $85.6 \%$ for sands, $117.6 \%$ for loams, and $206.6 \%$ for clays. The coefficients of variation of the air entry values measured on the permeability functions, $\ln \left(\psi_{b k}\right)$, seem unreasonably high. The COV of $\ln \left(\psi_{b k}\right)$ is $989 \%$ for sands, $2962 \%$ for loams, and $188.2 \%$ for clays. The high values of COV of $\ln \left(\psi_{b}\right)$ and remarkably high values of $\mathrm{COV}$ of $\ln \left(\psi_{b k}\right)$ are due to fact that some of the mean values of $\ln \left(\psi_{b}\right)$ and $\ln \left(\psi_{b k}\right)$ are significantly close to $0 \ln (\mathrm{kPa})$. The

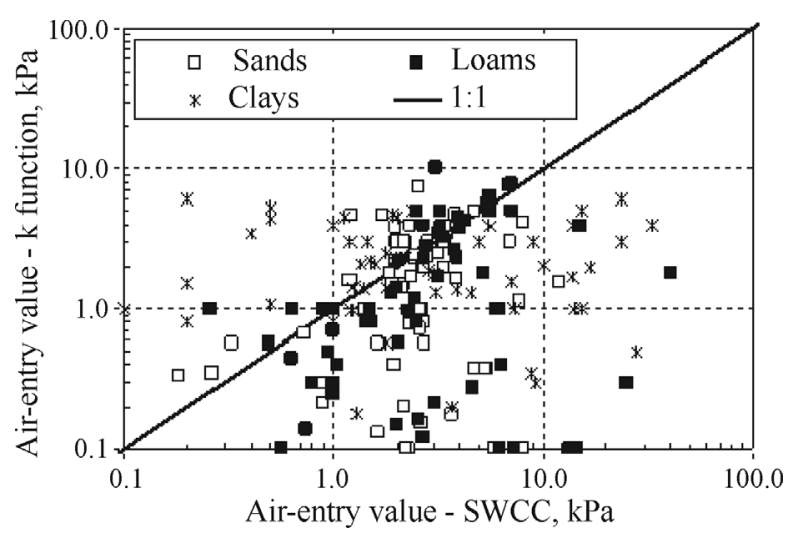

Figure 6 - Air-entry values obtained by best-fit of the soil-water characteristic curves and the hydraulic conductivity functions. values of COV are highly sensitive to small changes in the mean value when the mean value is between -1 and 1 $\ln (\mathrm{kPa})$ and close to $0 \ln (\mathrm{kPa})$. The sensitivity of COV to small mean values becomes obvious by examining its mathematical definition.

Figure 7 presents a plot of absolute values for the mean $\ln \left(\psi_{b}\right)$ and $\ln \left(\psi_{b k}\right) v s$. the computed COVs. Each data point corresponds to a distinct soil group gathered from the sampled soil records. The two lines surrounding the data points correspond to constant values of SD equal to 0.8 $\ln (\mathrm{kPa})$ and $2.1 \ln (\mathrm{kPa})$. Figure 7 shows that most data points are located between COV values of $75 \%$ and $125 \%$. However, when the mean values of $\ln \left(\psi_{b}\right)$ and $\ln \left(\psi_{b k}\right)$ fall between -0.5 and $0.5 \ln (\mathrm{kPa})$ and approach $0 \ln (\mathrm{kPa})$, significantly higher values of COV are obtained.

The coefficients of variation for $\ln \left(\psi_{b}\right)$ and $\ln \left(\psi_{b k}\right)$ show a clear trend with soil texture. The values of COV of $\ln \left(\psi_{b}\right)$ and $\ln \left(\psi_{b k}\right)$ increase for fine-grained soils. This result is anticipated since sands are known to have air entry values varying over a smaller range of soil suctions while loams and clays have air-entry values varying over a wider range.

In summary, the results obtained herein suggest that COV values between $75 \%$ and $125 \%$ can be adopted in cases where the mean values of $\ln \left(\psi_{b}\right)$ or $\ln \left(\psi_{b k}\right)$ are not within the -0.5 to $0.5 \ln (\mathrm{kPa})$ range. When the mean values of $\ln \left(\psi_{b}\right)$ or $\ln \left(\psi_{b k}\right)$ are within the -0.5 to $0.5 \ln (\mathrm{kPa})$ range, the COV values should be abandoned and the parameter uncertainty should be defined using a standard deviations between 0.8 and $2.1 \ln (\mathrm{kPa})$.

\subsection{Primary drainage slope}

The mean values obtained for the primary drainage slope, $\lambda_{d}$, were 1.446 for sands and 0.633 for loams. Primary drainage slope values for the SWCC of clay soils are not reported, since those soils were described using two parameters, $\psi_{b}$ and $a$. As observer for the air-entry value, the mean values of $\lambda_{d}$ for sands and loams disagreed with the median values, indicating non symmetric frequency distri-

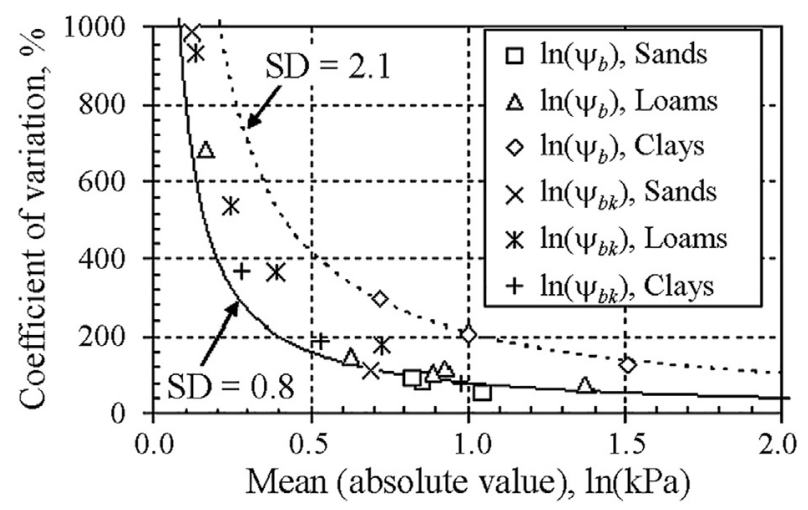

Figure 7 - Mean vs. the coefficient of variation of the natural logarithm of air-entry value obtained from the SWCC and from the $k$ function, $\ln \left(\psi_{b}\right)$ and $\ln \left(\psi_{b k}\right), \ln (\mathrm{kPa})$. 
butions. The closer agreement between the mean and median values of $\ln \left(\lambda_{d}\right)$ corroborates previous observations indicating the log normality of $\lambda_{d^{\prime}}$. It can also be observed that the values of $\lambda_{d}$ for sands are higher than those of loams, as expected. Loam soils tend to have broader poresize distributions than sands as reflected in the grain-size distributions.

The variability of the primary drainage slope was analyzed in the same manner as the previous parameters. The coefficient of variation of $\ln \left(\lambda_{d}\right)$ was $299.3 \%$ for sands and 93.5\% for loams. The COV of $\ln \left(\lambda_{d}\right)$ of loams is significantly lower than that of sands. This result does not reflect the wider grain-size distribution for loams and the narrower variation in grain-size distribution for sands. In fact, the results once again are influenced by low mean values of $\ln \left(\lambda_{d}\right)$ that approach zero. Figure 8 presents a plot of mean values of $\ln \left(\lambda_{d}\right) v s$. the computed COVs. The two lines plotted correspond to constant values of SD that encompass all the data points. The loam data points are closer to the maximum standard deviation line.

The results obtained herein suggest that a COV value between 75 and $100 \%$ can be adopted in cases where the mean values of $\ln \left(\lambda_{d}\right)$ are not within the -0.5 to +0.5 range. In cases where the mean values of $\ln \left(\lambda_{d}\right)$ are within the -0.5 to +0.5 range, the COV values suggested above should be abandoned and the parameter variability should be established using a range of standard deviations between 0.45 and 0.80 .

\subsection{Residual drainage slope}

The mean values for the residual drainage slope, $\lambda_{\text {res }}$, were 0.047 for sands and 0.090 for loams. The comparison between mean, median and global best-fit values of $\lambda_{\text {res }}$ and $\ln \left(\lambda_{\text {res }}\right)$ suggest once again the $\log$ normality of $\lambda_{\text {res }}$. It can also be observed that the values of $\lambda_{\text {res }}$ for sands were significantly lower than those of loams. This result was expected, since the smaller pores found in loam soils are capable of holding water up to relatively high soil suctions.

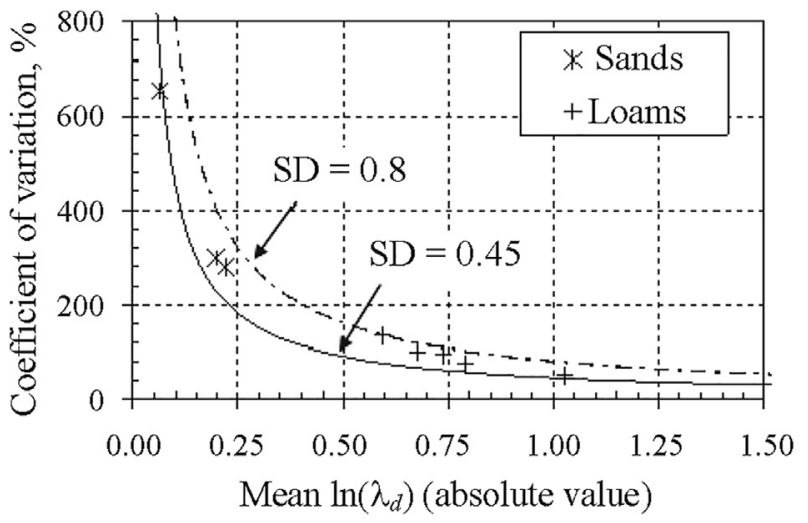

Figure 8 - Mean $v s$. the coefficient of variation of the natural logarithm of the primary drainage slope, $\ln \left(\lambda_{d}\right)$.
The coefficient of variation of $\ln \left(\lambda_{\text {res }}\right)$ is $13.7 \%$ for sands and $11.9 \%$ for loams. The COV of $\ln \left(\lambda_{\text {res }}\right)$ for loam soils was slightly lower than that of sands. The mean values of $\ln \left(\lambda_{\text {res }}\right)$ did not have a significant effect on the COV values since they did not fall within the -0.5 and 0.5 range. Figure 9 presents a plot of mean values of $\ln \left(\lambda_{\text {res }}\right) v s$. the computed COVs. The two lines plotted correspond to constant SD values of 0.20 and 0.45 . The sand data points are closer to a SD value of 0.45 but have higher mean values. Most data points are located between COV values of 8 and $12 \%$.

The results obtained herein suggest that a COV value between 8 and $12 \%$ can be adopted. Nevertheless, the mean values of $\ln \left(\lambda_{\text {res }}\right)$ should be verified. When the mean values of $\ln \left(\lambda_{\text {res }}\right)$ are within the $-0.5-0.5$ range, the COV values suggested above should be abandoned and the parameter variability should fall within a SD range between 0.2 and 0.45 .

\subsection{Saturated hydraulic conductivity}

Central tendency measures of the saturated hydraulic conductivity, $k_{s a t}$, can be misleading because its frequency distribution is positively skewed and its values may vary over several orders of magnitude. Just as with other previous parameters, statistical moments of the natural logarithm of the property are more meaningful and easier to interpret.

The values of $k_{\text {sat }}$ and $\ln \left(k_{s a t}\right)$ decreased for finer grained soils, as obviously expected. The mean values of $\ln \left(k_{s a t}\right)$ are -11.3 for sands, -12.6 for loams, and -16.0 for clays. The corresponding exponential values are $k_{\text {sat }}=1.23 \times 10^{-5} \mathrm{~m} / \mathrm{s}$ for sands, $k_{\text {sat }}=3.37 \times 10^{-6} \mathrm{~m} / \mathrm{s}$ for loams, and $k_{\text {sat }}=1.09 \times 10^{-7} \mathrm{~m} / \mathrm{s}$ for clays.

The variability of the saturated hydraulic conductivity was analyzed using the natural logarithm transformation. The coefficients of variation of $\ln \left(k_{\text {sat }}\right)$ were $15.3 \%$ for sands, $14.9 \%$ for loams, and $12.8 \%$ for clays. Apparently, the COV of $\ln \left(k_{\text {sat }}\right)$ slightly decrease for fine-grained soils. Figure 10 presents a plot of mean values of $\ln \left(k_{s a t}\right) v s$. the

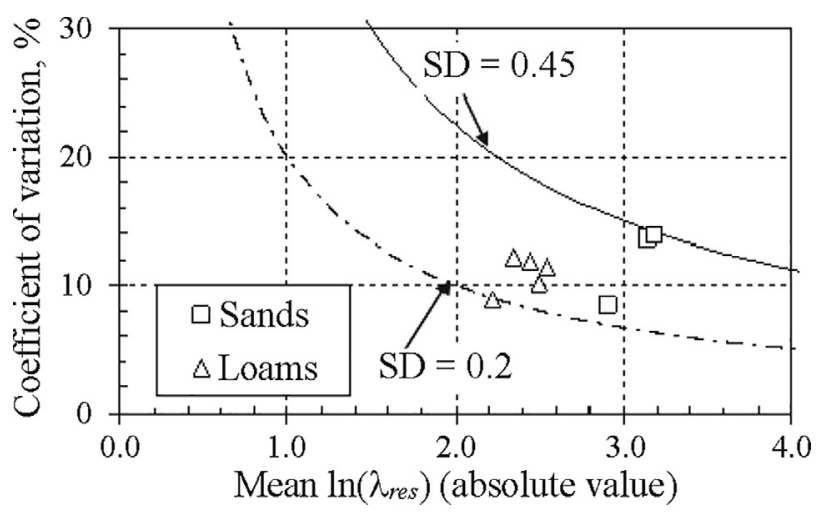

Figure 9 - Mean $v s$. the coefficient of variation of the natural logarithm of the residual drainage slope, $\ln \left(\lambda_{\text {res }}\right)$. 


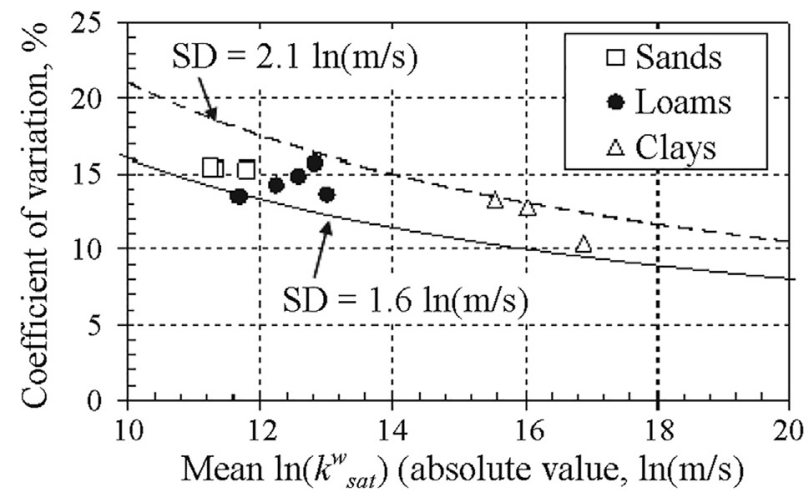

Figure 10 - Mean vs. the coefficient of variation of the natural logarithm of the saturated hydraulic conductivity, $\ln \left(k_{s a t}\right), \ln (\mathrm{m} / \mathrm{s})$.

computed COVs, in the same fashion as done for the previous parameters. The sand data points are closer to the maximum SD line, equal to $2.1 \mathrm{ln}(\mathrm{m} / \mathrm{s})$. The data points plotted in Fig. 10 indicate that the measures of COV of $\ln \left(k_{\text {sat }}\right)$ appear to show little variation with the mean values. Therefore, results presented herein suggest that a value of COV of $\ln \left(k_{\text {sat }}\right)$ between 13 and $16 \%$ is representative.

\subsection{Hydraulic conductivity function slope}

The mean values of the hydraulic conductivity function slope, $\eta$, were 4.037 for sands, 2.792 for loams, and 2.095 for clays. The values of $\eta$ for sands are higher than those of loams and clays, as expected. This trend was observed for the minimum, maximum, median, mean values, and global best-fit values.

The coefficients of variation of $\ln (\eta)$ are $39.9 \%$ for sands, $55.0 \%$ for loams, and $48.6 \%$ for clays. The COV of $\ln (\eta)$ does not show any clear relationship with soil texture, though it appears to slightly increase for fine-grained soils. Figure 11 presents a plot of mean values of $\ln (\eta) v s$. computed COVs. The two lines shown correspond to constant $\mathrm{SD}$ values of 0.28 and 0.58 . One outliner was ignored. Most data points are within a COV range between 40 and $55 \%$. The data points plotted in Fig. 11 do not indicate any clear

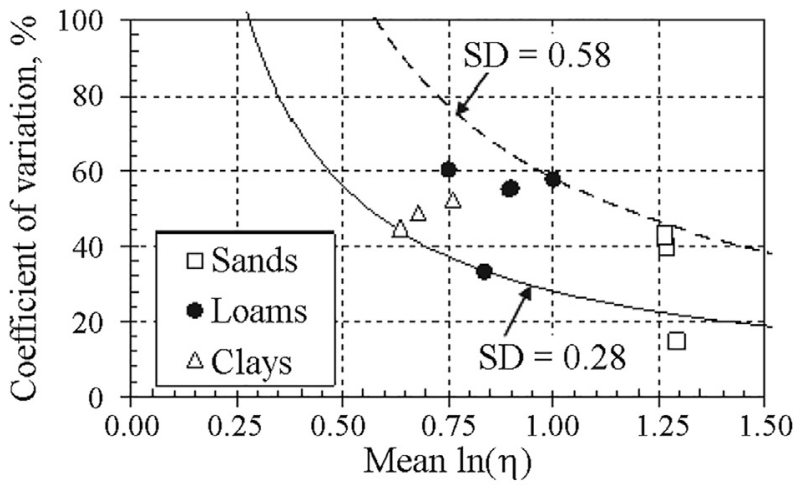

Figure 11 - Mean vs. the coefficient of variation of the natural logarithm of the hydraulic conductivity function slope, $\ln (\eta)$. relationship between the $\mathrm{COV}$ measures for $\ln (\eta)$ and the mean values. The results obtained herein suggest that COV values of $\ln (\eta)$ should be between 40 and $55 \%$.

\section{Correlation Coefficients Between Unsaturated Soil Parameters}

The correlation coefficient, $\rho$, between each pair of unsaturated soil parameters was determined with the aid of Minitab 13 (Minitab Inc., 2000). The parameters studied were $n, \ln \left(\psi_{b}\right), \ln \left(\lambda_{d}\right), \ln \left(\psi_{\text {res }}\right), \ln \left(k_{s a t}\right), \ln \left(\lambda_{b k}\right)$, and $\ln (\eta)$. A two-tailed correlation test was applied. The null hypothesis of the test performed was H0: correlation coefficient of zero. $P$-values were computed to represent the probability of making a type 1 error, which is "rejecting the null hypothesis when it is true." The smaller the $P$-value, the higher the likelihood that the parameters are correlated. The cut-off value used was 5\%, that is, the null hypothesis was rejected when the $p$-value was less than $5 \%$.

Table 5 presents the results of the correlation analyses. The correlation coefficients are presented for all pairs of variables. Some correlation coefficients are accompanied by a star $(*)$, which indicates that the $p$-value obtained was less than $5 \%$.

The correlation coefficients presented in Table 5 were calculated considering all data records as a single group and also considering the three soil groups $(S a, L$, and $C)$ individually. The $p$-values tended to decrease when the data records where considered as a single group, except in a few cases. An increase in the number of data points generally results in a decrease in the uncertainty associated with a type 1 error.

Porosity did not present substantial correlation with any parameter, with exception of the parameter $\ln \left(\lambda_{\text {res }}\right)$. The correlation coefficient between $n$ and $\ln \left(\lambda_{\text {res }}\right)$ did not have a $p$-value lower than $5 \%$ for all soil groups. Similarly, the variable $\ln \left(\lambda_{\text {res }}\right)$ did not present substantial correlation with any other parameter with the exception of the aforementioned correlation with porosity and some mild correlation with $\ln \left(\psi_{b}\right)$.

Noteworthy correlations involving the air-entry value were found when considering both $\ln \left(\psi_{b}\right)$ and $\ln \left(\psi_{b k}\right)$. While $\ln \left(\psi_{b}\right)$ presented considerable correlations with the SWCC-related parameters, $\ln \left(\psi_{b k}\right)$ showed significant correlations with the parameters related to the $k$ function. The parameters $\ln \left(\psi_{b}\right)$ and $\ln \left(\lambda_{d}\right)$ presented correlation coefficients that varied from +0.374 to +0.587 . This significantly positive correlation indicates that soils with larger air-entry value tend to be the same soils that have "poorly graded" pore-size distributions. The parameters $\ln \left(\psi_{b}\right)$ and $\ln \left(\lambda_{\text {res }}\right)$ presented correlation coefficients that varied from +0.211 to +0.281 . This correlation was not as anticipated since there would appear to be little physical meaning for a relationship between the air-entry value and the residual drainage slope. 
Table 5 - Correlation matrix for unsaturated soil properties.

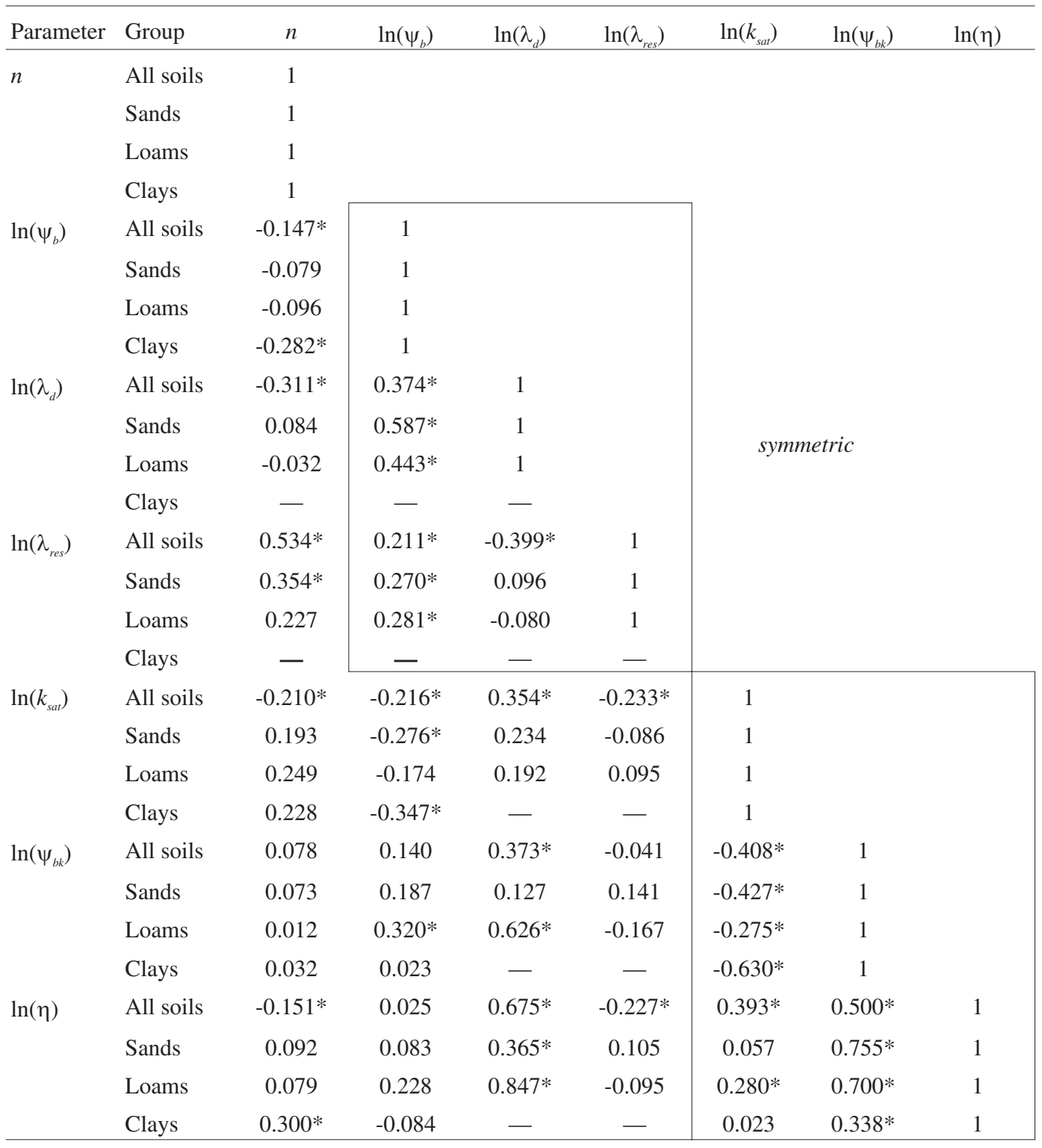

Note: $\left.{ }^{*}\right)$ indicates the correlation coefficients for which the $p$-value is less than $5 \%$.

The parameters $\ln \left(\psi_{b k}\right)$ and $\ln \left(k_{s a t}\right)$ presented moderate to high correlation coefficients that varied from -0.275 to -0.630 . The negative correlation between $\ln \left(\psi_{b}\right)$ and $\ln \left(k_{s a t}\right)$ was also expected since the same factors that cause higher air-entry values are responsible for lower values of $k_{\text {sat }}$, such as larger fractions of fines. The parameters $\ln \left(\psi_{b k}\right)$ and $\ln (\eta)$ presented correlation coefficients that varied from +0.338 to +0.755 .

Finally, the parameters $\ln (\eta)$ and $\ln \left(\lambda_{d}\right)$ presented high degrees of correlation that varied from +0.365 to +0.847 . The high degree of positive correlation was as anticipated. Several mechanistic models of prediction for the hydraulic conductivity function indicate that the slope of the $k$ function increases with increasing values of $\lambda_{d}(e . g$., Brooks \& Corey, 1964).

\section{Summary of Suggested Typical Values}

The information presented and interpreted in the previous sections is summarized in a convenient manner in Tables 6-8. Table 6 presents a summary of the mean values for the unsaturated soil parameters $n, \ln \left(\psi_{b}\right), \ln \left(\lambda_{d}\right), \ln \left(\lambda_{\text {res }}\right)$, $\ln \left(k_{\text {sat }}\right)$, and $\ln (\eta)$ along with the exponential value of all variables, except for porosity. Independent best estimates for mean air-entry values are suggested for $\ln \left(\psi_{b}\right)$ and $\ln \left(\psi_{b k}\right)$. The values presented in Table 6 are suggested as the best measures of central tendency for each main soil group. 
Porosity can be considered normally distributed and all the remaining parameters presented in Table 6 can be assumed to be log normally distributed. It is important to point out that the similar mean values of air-entry value for different textural classes are explained by an increase in COV and range of values for finer grained soils. As a result, the mean values of the entire population remain relatively low. The wide variation of air-entry values for finer-grained soils can be attributed, for example, to the importance of fabric to the pore-size distribution.

Table 7 presents a summary of the coefficients of variation for the unsaturated soil parameters $n, \ln \left(\psi_{b}\right)$, $\ln \left(\lambda_{d}\right), \ln \left(\lambda_{\text {res }}\right), \ln \left(k_{\text {sat }}\right)$, and $\ln (\eta)$. The values of $\ln \left(\psi_{b}\right)$ were established by combining the results obtained for $\ln \left(\psi_{b}\right)$ and $\ln \left(\psi_{b k}\right)$. General ranges for all soil types are presented along with specific information for each main soil group, $S a, L$, and $C$.

Some ranges for the coefficient of variation suggested in Table 7 are not applicable when the mean value of the parameter is within the range -0.5 and 0.5 . In these cases the standard deviation values provided in Table 7 can be adopted.
Table 8 presents a summary of the correlation coefficients for pairs for the following unsaturated soil parameters, $n, \ln \left(\psi_{b}\right), \ln \left(\lambda_{d}\right), \ln \left(\lambda_{\text {res }}\right), \ln \left(k_{\text {sat }}\right)$, and $\ln (\eta)$. The correlation coefficients associated with the air-entry value were established by combining the results obtained for $\ln \left(\psi_{b}\right)$ and $\ln \left(\psi_{b k}\right)$. Average values applicable to all soil types were established. The values presented in Table 8 are suggested as general guideline values applicable for any soil type.

\section{Concluding Remarks}

This paper presented a comprehensive statistical study of hydraulic properties of unsaturated soil. The primary objective was to present approximate uncertainty values that could be used in probabilistic geotechnical analyses. The property functions studied were the soil-water characteristic curve and the hydraulic conductivity function. The statistical study was based on a large database of soils. The study was undertaken considering three soil groups based on the USDA textural classification system; namely, sands, loams, and clays.

A methodology was developed for the statistical assessment of unsaturated soil property functions. Appropriate nonlinear unsaturated soil property equations and fitting

Table 6 - Mean values for unsaturated soil properties by soil group.

\begin{tabular}{lccc}
\hline Group & Sands & Loams & Clays \\
\hline$n$ & 0.410 & 0.500 & 0.534 \\
$\ln \left(\psi_{b}\right), \ln (\mathrm{kPa})$ & $0.856(2.35)$ & $0.927(2.53)$ & $0.999(2.71)$ \\
$\ln \left(\lambda_{d}\right)$ & $0.198(1.219)$ & $-0.737(0.478)$ & - \\
$\ln \left(\lambda_{\text {res }}\right)$ & $-3.141(0.043)$ & $-2.445(0.087)$ & - \\
$\ln \left(k_{\text {sat }}\right), \ln (\mathrm{m} / \mathrm{s})$ & $-11.34\left(1.19 \times 10^{-5}\right)$ & $-12.58\left(3.44 \times 10^{-6}\right)$ & $-16.03\left(1.09 \times 10^{-7}\right)$ \\
$\ln \left(\psi_{b k}\right), \ln (\mathrm{kPa})$ & $0.119(1.13)$ & $-0.047(0.95)$ & $0.527(1.69)$ \\
$\ln (\eta)$ & $1.268(3.554)$ & $0.895(2.447)$ & $0.682(1.978)$ \\
\hline
\end{tabular}

Note: Values between brackets indicate the exponential of the variable.

Table 7 - Coefficients of variation and standard deviations of unsaturated soil properties.

\begin{tabular}{|c|c|c|c|c|}
\hline \multirow[t]{2}{*}{ Soil parameter } & \multirow{2}{*}{$\begin{array}{l}\text { General ranges for all soils of the Coefficient of } \\
\text { Variation (COV) and Standard Deviation (SD) }\end{array}$} & \multicolumn{3}{|c|}{ Coefficient of variation } \\
\hline & & Sands & Loams & Clays \\
\hline$n$ & $\mathrm{COV}=13-19 \%$ & $13 \%$ & $17 \%$ & $19 \%$ \\
\hline $\ln \left(\psi_{b}\right)$ & $\begin{array}{l}\mathrm{COV}=75-205 \% \text { for }-0.5>E\left[\ln \left(\psi_{b}\right)\right]>0.5 \ln (\mathrm{kPa}) \\
\text { otherwise, } S D=0.8-2.1 \ln (\mathrm{kPa})\end{array}$ & $85 \%$ & $115 \%$ & $205 \%$ \\
\hline $\ln \left(\lambda_{d}\right)$ & $\begin{array}{l}\mathrm{COV}=75-100 \% \text { for }-0.5>E\left[\ln \left(\lambda_{d}\right)\right]>0.5 \\
\text { otherwise, } S D=0.45-0.80\end{array}$ & $100 \%$ & $90 \%$ & - \\
\hline $\ln \left(\lambda_{r e s}\right)$ & $\begin{array}{l}\mathrm{COV}=8-14 \% \text { for }-0.5>E\left[\ln \left(\lambda_{\text {res }}\right)\right]>0.5 \\
\text { otherwise, } S D=0.20-0.45\end{array}$ & $14 \%$ & $12 \%$ & - \\
\hline $\ln \left(k_{\text {sat }}\right)$ & $\mathrm{COV}=13-16 \%$ & $16 \%$ & $15 \%$ & $13 \%$ \\
\hline $\ln (\eta)$ & $\mathrm{COV}=40-55 \%$ & $40 \%$ & $55 \%$ & $50 \%$ \\
\hline
\end{tabular}


Table 8 - Correlation matrix for unsaturated soil properties.

\begin{tabular}{llccccc}
\hline Parameter & $n$ & $\ln \left(\psi_{b}\right)$ & $\ln \left(\lambda_{d}\right)$ & $\ln \left(\lambda_{\text {res }}\right)$ & $\ln \left(k_{\text {sat }}\right)$ & $\ln (\eta)$ \\
\hline$n$ & 1 & \multicolumn{3}{l}{ symmetric } & \\
$\ln \left(\psi_{b}\right)$ & 0 & 1 & & & & \\
$\ln \left(\lambda_{d}\right)$ & 0 & 0.45 & 1 & & & \\
$\ln \left(\lambda_{\text {res }}\right)$ & 0 & 0.25 & 0 & 1 & & \\
$\ln \left(k_{\text {sat }}\right)$ & 0 & -0.40 & 0 & 0 & 1 & 1 \\
$\ln (\eta)$ & 0 & 0 & 0.60 & 0 & 0.60 & \\
\hline
\end{tabular}

parameters were described. All equation parameter were shown to have a clearly defined feature on the soil property function and the equation parameters were mathematically independent. The Gitirana Jr. \& Fredlund (2004) soil-water characteristic curve equation was used and a bilinear equation was adopted for hydraulic conductivity. The soil parameters studied are: $n, \psi_{b}, \lambda_{d}, \lambda_{\text {res }}, k_{s a t}, \psi_{b k}$, and $\eta$.

Normality tests showed that unsaturated soil parameters can be considered to be log normally distributed. Various central tendency measures were evaluated. The mean values of the natural logarithm of the soil parameters provided the best central tendency measure. Uncertainty measures were presented in terms of standard deviations and coefficients of variation. Fairly constant coefficients of variations were determined for various soil groups. However, some unsaturated soil parameters have mean values that may fall within a -0.5 to 0.5 range, making the coefficient of variation a poor measure of uncertainty. A combination of standard deviation and coefficient of variation values were proposed for these parameters.

Correlation matrices were determined considering the three selected soil groups as well as considering all datasets as one large soil group. Correlations involving the air-entry value were found considering both $\ln \left(\psi_{b}\right)$ and $\ln \left(\psi_{b k}\right)$. While $\ln \left(\psi_{b}\right)$ presented considerable correlations with the SWCC-related parameters, $\ln \left(\psi_{b k}\right)$ showed significant correlations with the parameters related to the $k$ function. The parameters $\ln \left(\psi_{b k}\right)$ and $\ln \left(k_{s a t}\right)$ presented moderate to high negative correlations, as anticipated. The pairs $\ln \left(\psi_{b k}\right)-\ln (\eta), \ln (\eta)-\ln \left(\lambda_{d}\right)$, and $\ln (\eta)-\ln \left(k_{s a t}\right)$ presented moderate to strong positive correlation.

The coefficients of variation and standard deviations presented herein include diverse sources of uncertainty. Individual sources of parameter variability could not be assessed. Nevertheless, the presented standard deviations and coefficients of variations serve as a general indication and as a first approximation. The information presented herein can be refined in future studies as further data is collected and analyzed.

\section{Acknowledgments}

The authors would like to thank the "Conselho Nacional de Desenvolvimento Científico e Tecnológico - CNPq", Brazil, Canadian Pacific Railway, Saskatchewan Highways and Transportation, and NSERC for financial support.

\section{References}

ASTM D 2487-93 (1993). Standard Classification of Soils for Engineering Purposes (Unified Soil Classification System).

Bates, D. \& Watts, D. (1988). Nonlinear Regression Analysis and its Applications. John Wiley \& Sons, New York, United States of America.

Benson, C.H.; Daniel, D.E. \& Boutwell, G.P. (1999). Field performance of compacted clay liners. Journal of Geotechnical and Geoenvironmental Engineering, ASCE, 125(5):390-403.

Brooks, R.H. \& Corey, A.T. (1964). Hydraulic properties of porous media. Hydrology. Paper No. 3, Colorado State University, Fort Collins, Colorado, 27 p.

Dai, S.-H. \& Wang, M.-O. (1992). Reliability Analysis in Engineering Applications. Van Nostrand Reinhold, New York.

D’Augostino, R.B. \& Stevens, M.A. (1986). Goodness-ofFit Techniques. Marcel Dekker Inc., New York, 576 p.

Duncan, M. (2000). Factors of safety and reliability in geotechnical engineering. Journal of Geotechnical and Geoenvironmental Engineering, ASCE, 126(4):307316.

Faulkner, B.R.; Lyon, W.G.; Khan, F.A. \& Chattopadhyay, S. (2003). Modeling leaching of viruses by the Monte Carlo method. Water Research, 37(19):4719-4729.

Fredlund, D.G. \& Dahlman, A.E. (1971). Statistical geotechnical properties of glacial lake Edmonton sediments. Proc. $1^{\text {st }}$ International Conference on Applications of Statistics and Probability to Soil and Structural Engineering, Hong Kong, pp. 204-228.

Fredlund, D.G. \& Xing, A. (1994). Equations for the soilwater characteristic curve. Canadian Geotechnical Journal, 31(4):533-546. 
Gitirana Jr., G.F.N. \& Fredlund, D.G. (2004). Soil-water characteristic curve equation with independent properties. Journal of Geotechnical and Geoenvironmental Engineering, ASCE, 130(2):209-212.

Hammitt, G.M. (1966). Statistical analysis of data from a comparative laboratory test program sponsored by ACIL. Miscellaneous Paper 4-785, U.S. Army Engineering Waterways Experiment Station, Corps of Engineers.

Harr, M.E. (1987). Reliability-Based Design in Civil Engineering. John Wiley and Sons, New York, 291 p.

Huang, S.; Barbour, S.L. \& Fredlund, D.G. (1998). Development and verification of a coefficient of permeability function for a deformable unsaturated soil. Canadian Geotechnical Journal, 35(3):411-425.

Krahn, J. \& Fredlund, D.G. (1983). Variability in the engineering properties of natural soil deposits. Proc. $4^{\text {th }} \mathrm{In}$ ternational Conference on Applications of Statistics and Probability in Soil and Structural Engineering, Florence, Italy, pp. 1017-1029.

Kulhawy, F.H. (1992). On the evaluation of soil properties. ASCE Geotech. Special Publication 31, Reston, pp. 95-115.

Lacasse, S. \& Nadim, F. (1997). Uncertainties in Characterizing Soil Properties. Publication No. 201, Norwegian Geotechnical Institute, Olso, Norway, pp. 49-75.

Ladd, C.C. (1983). Geotechnical exploration in clay deposits with emphasis on recent advances in laboratory and in situ testing and analysis of data scatter. Journal of Civil and Hydraulic Engineering, Taiwan, 10(3):3-35.

Lumb, P. (1966). The variability if natural soils. Canadian Geotechnical Journal, 3(2):74-97.

Meyer, P.D.; Rockhold, M.L. \& Gee, G.W. (1997). Uncertainty analyses of infiltration and subsurface flow and transport for SDMP sites. NUREG/CR-6565. U.S. NRC.

Minitab Inc. (2000). Minitab User's Manual, Version 13. Copyright 2000. Minicab Inc. State College, PA.

Mishra, S.; Parker, L.C. \& Singhal, N. (1989). Estimation of soil hydraulic properties and their uncertainty from particle size distribution data. Journal of Hydrology, 108(1):1-18.

Nielsen, D.R.; Biggar, J.W. \& Erh, K.T. (1973). Spatial variability of field-measured soil-water properties. Hilgardia, 42(7):215-260.

Padilla, J.D. \& Vanmarcke, E.H. (1974). Settlement of structures on shallow foundations: A probabilistic analysis. Res. Pes. R74-9, MIT, Cambridge, Mass.

Phoon, K.-K. \& Kulhawy, F.H. (1999a). Characterization of geotechnical variability. Canadian Geotechnical Journal, 36(4):612-624.

Phoon, K.-K. \& Kulhawy, F.H. (1999b). Evaluation of geotechnical property variability. Canadian Geotechnical Journal, 36(4):625-639.
Phoon, K.-K.; Santoso, A. \& Quek, S.-T. (2010). Probabilistic analysis of soil-water characteristic curves. Journal of Geotechnical and Geoenvironmental Engineering, ASCE, 136(3):445-455.

Rawls, W.J.; Gimenez, R. \& Grossman, R. (1998). Use of soil texture, bulk density, and slope of the water retention curve to predict saturated hydraulic conductivity. Trans ASAE. 41(4):983-988.

Schultze, E. (1971). Frequency distributions and correlations of soil properties. Proc. First International Conference on Applications of Statistics and Probabilistic in Soil and Structure Engineering, Hong Kong. pp. 371387.

Soil Survey Staff (1975). Soil Taxonomy: A Basic System of Soil Classification for Making and Interpreting Surveys. $2^{\text {nd }}$ Ed. USDA-SCS Agriculture Handbook, U.S. Gov. Print. Office, Washington, D.C., 869 p.

SoilVision Systems (2005). SoilVision User's Guide - A Knowledge-based System for Geotechnical Engineers. Version 4.0. Saskatoon, SK, , 149 p.

Tan, C.P.; Donald, I.B. \& Melchers, R.E. (1993). Probabilistic slip circle analysis of earth and rockfill dams. Proc. Conference on Probabilistic Methods in Geotechnical Engineering, Camberra, pp. 281-288.

Whitman, R.V. (1984). Evaluating calculated risk in geotechnical engineering. ASCE Geotechnical Engineer Journal. 110(2):145-189.

Zapata, C.E.; Houston, W.N.; Houston, S.L. \& Walsh, K.D. (2000). Soil-water characteristic curve variability. Shackelford, C.D., Houston S.L., \& Chang N-Y. (eds), Advances in Unsaturated Geotechnics, ASCE, GeoInstitute Geotechnical Special Publication No. 99, August 5-8, 2000, pp. 84-124.

\section{List of Symbols}

COV: coefficient of variation

$E$ : mean

$H C V$ : highest conceivable value

$k$ : hydraulic conductivity

$k_{\text {sat }}:$ saturated hydraulic conductivity

$L C V$ : lowest conceivable value

$n$ : porosity

$S D$ : standard deviation

$S$ : degree of saturation

$S_{\text {res: }}:$ residual degree of saturation

$\eta$ : slope of the hydraulic conductivity function

$\lambda_{d}$ : primary drainage slope

$\lambda_{\text {res }}$ : residual drainage slope

$\rho$ : correlation coefficient

$\psi$ : soil suction

$\psi_{b}$ : air-entry value

$\psi_{b k}$ : break point of the hydraulic conductivity function

$\psi_{\text {res }}:$ residual suction 